\title{
Densities, Viscosities and Refractive Indices of Ternary System Cyclohexane + Cyclohexanol + Cyclohexanone at 293.15, 298.15 and 303.15 K
}

\begin{abstract}
MARIA MAGDALENA BUDEANU*, VASILE DUMITRESCU
Chemistry Department, Petroleum and Gas University of Ploiesti, 39 Bucuresti Blvd., 100520, Ploiesti, Romania

Densities ( $\rho)$, viscosities $(\eta)$ and refractive indices $\left(n_{\rho}\right)$ of the ternary system cyclohexane + cyclohexanol + cyclohexanone were measured at 293.15, 298.15 and $298.15 \mathrm{~K}$ and atmospheric pressure, over the whole composition range. The experimental values of densities and viscosities were correlated with temperature using a linear equation and Guzman equation respectively. Viscosity results were fitted with Grunberg-Nissan equation and Heric-Brewer equation. Different refractive index mixing rules (Arago-Biot, Dale-Glastone, Newton and Lorent-Lorenz) were studied for this ternary system. The functions of activation of viscous flow were also calculated and their variations with compositions have been discussed.
\end{abstract}

Keywords: ternary mixtures, density, viscosity, refractive index

Thermophysical properties of multi-component liquid mixtures are essential for process designing as well as for understanding structural and packing changes of molecules in mixtures. The design and operation of processes that involve non-electrolyte mixtures require knowledge of rigorous models or experimental data to represent the non-ideality of mixtures [1].

Density, viscosity and refractive index are the physicochemical properties which provide important information, useful for different problems in chemical engineering in order to develop industrial processes, as well as for database applications and model formulations [2]. The correct values of liquid density are important because they are involved in the equations of heat, mass and momentum transfer [3].

Cyclohexane is widely used as a solvent, polar additive, dilution initiator, structure regulator and active additive in the synthesis of copolymer, resins and rubber [4].

Cyclohexanol finds applications as an intermediate substance in the production of nylon and plasticizers. It acts as a stabilizer in soap and detergent making and as a solvent in paint and textile industries [5].

Cyclic and linear alcohols are associated through the hydrogen bond in the pure state as well as in mixtures. The degree of association in alkanols containing cyclic alkyl group is very low due to steric factors [6].

Cyclic ketones are important intermediates in the synthesis of many organic compounds important for the chemical, pharmaceutical, and cosmetic industries [7-9].

Cyclohexanone can be used as raw material in the production of cycloalkanes, caprolactam and the monomers used for the synthesis of Nylon 6 and $66[10,11]$.

This paper reports densities, viscosities and refractive indices of ternary mixtures of cyclohexane + cyclohexanol + cyclohexanone as function of composition at 293.15, 298.15 and $303.15 \mathrm{~K}$ and atmospheric pressure. A literature survey has shown that the thermophysical properties for the ternary system studied have not been reported.

\section{Experimental part}

The chemicals cyclohexane (mole fraction purity > 0.997) was supplied by Merck, cyclohexanol (mole fraction purity > 0.998) and cyclohexanone (mole fraction purity
$>0.98$ ) were obtained from Chemical Company. The purity was verified by chromatographic analysis. The mole fractions were determined by weighing with a precision of $\pm 10^{-4} \mathrm{~g}$. The experimental error in mole fraction is estimated to be \pm 0.0001 .

The densities of the pure components and of the ternary solutions are measuring using a calibrated glass pycnometer having a bulb volume of $10 \mathrm{~cm}^{3}$. The pycnometer filled with a liquid was kept in a thermostatically bath (maintained constant to $\pm 0.05 \mathrm{~K}$ ) for $15 \mathrm{~min}$ to achieve thermal equilibrium [12]. The estimated uncertainty for density was $\pm 0.0003 \mathrm{~g} \mathrm{~cm}^{-3}$.

Viscosities were determined with an Ubbelohde kinematic viscometer [13] that was kept in a vertical position in a thermostatically bath ( $U 10$ constant to \pm $0.05 \mathrm{~K}$ ).

The kinetic viscosity was calculated using the relation:

$$
v=A t-B / t
$$

where $v$ is the kinematic viscosity, $t(s)$ is its flow time in the viscometer, and $A$ and $B$ are characteristic constants of the used viscometer. The constants $A$ and $B$ were determined by using bidistilled water and benzene as the calibrating liquids. Accuracy of time measurement is \pm $0.01 \mathrm{~s}$.

The dynamic viscosity was determined from the equation:

$$
\eta=v \rho
$$

where $\rho$ is the density of the liquid. The precision of the viscosity to be $\pm 0.0004 \mathrm{mPa}$ s. The refractive indices of pure liquids and their ternary mixtures were measured using a thermostatted Abbe refractometer. Calibration of the instruments was done by measuring the refractive indices of double-distilled water and toluene at known temperature. The values of refractive index were obtained using sodium $D$ light.

The temperature of the test liquids between the prism of refractometer during the measurements was maintained to an accuracy of $\pm 0.05 \mathrm{~K}$ by circulating water through the jacket around the prism from a controlled thermostatic bath and the temperature was measured with an digital thermometer connected with the prism jacket

\footnotetext{
* email: maria.budeanu@upg-ploiesti.ro
} 
[14]. The error in refractive indices measurements was less than 0.0002 units. Each measurement was repeated at least three times and the results were averaged.

\section{Results and discussions}

The measured densities, viscosities and refractive indices of the pure components are presented in table 1.

Cyclohexane densities values reported in the literature differ than our values with a maximum $0.1 \%$. For cyclohexanol, densities values published in the literature differ from our experimental data with a maximum $0.11 \%$ and for cyclohexanone values differ with maximum $0.04 \%$. Viscosity values reported in the literature differ than our data with a maximum $0.95 \%$ for cyclohexane, with maximum $2.8 \%$ for cyclohexanol and for cyclohexanone with maximum $1.2 \%$.

The differences between measured and literature data of refractive indices are less than $0.02 \%$ for cyclohexane, less than $0.01 \%$ for cyclohexanol and maximum $0.05 \%$ for cyclohexanone. The densities, viscosities and refractive indices of the ternary mixtures of cyclohexane + cyclohexanol + cyclohexanone are reported in tables 2-4.

Table 1

EXPERIMENTAL AND LITERATURE VALUES FOR DENSITIES $(\rho)$ AND VISCOSITIES $(\eta)$ AND REFRACTIVE INDICES $\left(n_{D}\right)$ OF THE PURE COMPONENTS

\begin{tabular}{|c|c|c|c|c|c|c|c|}
\hline \multirow[t]{2}{*}{ Component } & \multirow[t]{2}{*}{$T / \mathrm{K}$} & \multicolumn{2}{|c|}{$\rho / \mathrm{g} \mathrm{cm}^{-3}$} & \multicolumn{2}{|c|}{$\eta / \mathrm{mPa} s$} & \multicolumn{2}{|c|}{$n$} \\
\hline & & $\operatorname{Exp}$ & Lit & Exp & Lit & Exp & Lit \\
\hline \multirow[t]{3}{*}{ Cyclohexane } & 293.15 & 0.7771 & - & 0.9689 & - & 1.4256 & - \\
\hline & 298.15 & 0.7731 & $0.77382[15]$ & $0.8944^{-}$ & $0.903[15]^{--}$ & 1.4238 & $1.4235[16]$ \\
\hline & 303.15 & 0.7683 & $0.7691[15]$ & 0.8161 & $0.821[15]$ & 1.4227 & - \\
\hline \multirow[t]{3}{*}{ Cyclohexanol } & 293.15 & 0.9498 & - & 61.1023 & - & 1.4655 & - \\
\hline & 298.15 & 0.9461 & $0.94504[17]$ & 51.0841 & - & 1.4643 & $1.46445[17]$ \\
\hline & 303.15 & $0.9420^{\circ}$ & $0.9418[18]$ & 39.8935 & $41.072[19]$ & 1.4628 & - \\
\hline \multirow[t]{3}{*}{ Cyclohexanone } & 293.15 & 0.9463 & $0.94644[20]$ & 2.3030 & $2.3318[8]$ & 1.4509 & - \\
\hline & 298.15 & 0.9430 & $0.9429[1]$ & 2.0835 & $2.1016[8]$ & 1.4495 & $1.4503[21]$ \\
\hline & 303.15 & 0.9399 & 0.9403 [8] & 1.9030 & $1.9045[8]$ & 1.4482 & - \\
\hline
\end{tabular}

\begin{tabular}{|c|c|c|c|c|}
\hline & & \multicolumn{3}{|c|}{ Density $\mathrm{gcm}^{-3}$} \\
\cline { 2 - 5 } & $x_{1}$ & \multicolumn{3}{|c|}{ Temperature $/ \mathrm{K}$} \\
\hline 0.0981 & & 293.15 & 298.15 & 303.15 \\
\hline 0.1462 & 0.1053 & 0.9291 & 0.9264 & 0.9232 \\
0.1957 & 0.2005 & 0.9221 & 0.9178 & 0.9139 \\
0.2161 & 0.2200 & 0.9139 & 0.9082 & 0.9040 \\
0.2986 & 0.3049 & 0.9096 & 0.9043 & 0.9006 \\
0.3993 & 0.3973 & 0.8934 & 0.8885 & 0.8848 \\
0.4484 & 0.4574 & 0.8796 & 0.8744 & 0.8704 \\
0.1079 & 0.7868 & 0.9295 & 0.8657 & 0.8616 \\
0.1501 & 0.6956 & 0.9231 & 0.9260 & 0.9219 \\
0.1994 & 0.5982 & 0.9141 & 0.9176 & 0.9135 \\
0.2514 & 0.4950 & 0.8994 & 0.9091 & 0.9052 \\
0.2982 & 0.4027 & 0.8908 & 0.8961 & 0.8926 \\
0.3904 & 0.1950 & 0.8780 & 0.8866 & 0.8821 \\
0.4455 & 0.1039 & 0.8703 & 0.8736 & 0.8700 \\
0.8128 & 0.0922 & 0.8092 & 0.8644 & 0.8600 \\
0.5852 & 0.2030 & 0.8468 & 0.8027 & 0.7983 \\
0.6004 & 0.2018 & 0.8446 & 0.8411 & 0.8351 \\
0.4965 & 0.2535 & 0.8612 & 0.8390 & 0.8346 \\
0.3999 & 0.2965 & 0.8732 & 0.8560 & 0.8522 \\
0.1956 & 0.4168 & 0.9111 & 0.8696 & 0.8659 \\
0.1002 & 0.4509 & 0.9304 & 0.9075 & 0.9037 \\
\hline & & & 0.9254 & 0.9211 \\
\hline
\end{tabular}

Table 2

EXPERIMENTAL VALUES FOR DENSITIES $(\rho)$ OF THE CYCLOHEXANE $\left(\mathrm{x}_{1}\right)+$ CYCLOHEXANOL $\left(X_{2}\right)+$ CYCLOHEXANONE SYSTEM

\begin{tabular}{|c|c|c|c|c|}
\hline & & \multicolumn{3}{|c|}{ Viscosity /mPa s } \\
\cline { 3 - 5 }$x_{1}$ & $x_{2}$ & \multicolumn{3}{|c|}{ Temperature /K } \\
\hline & & 293.15 & 298.15 & 303.15 \\
\hline 0.0981 & 0.1053 & 2.3956 & 2.1628 & 1.9493 \\
0.1462 & 0.1740 & 2.6490 & 2.2919 & 2.0503 \\
0.1957 & 0.2005 & 2.5976 & 2.2587 & 2.0188 \\
0.2161 & 0.2200 & 2.6499 & 2.3317 & 2.1027 \\
0.2986 & 0.3049 & 2.9022 & 2.5796 & 2.3532 \\
0.3993 & 0.3973 & 3.5716 & 3.0623 & 2.6505 \\
0.4484 & 0.4574 & 4.1066 & 3.5153 & 2.9738 \\
0.1079 & 0.7868 & 17.8073 & 13.8180 & 11.0621 \\
0.1501 & 0.6956 & 11.5411 & 9.3446 & 7.6453 \\
0.1994 & 0.5982 & 7.8686 & 6.6811 & 5.5135 \\
0.2514 & 0.4950 & 5.1674 & 4.3482 & 3.8057 \\
0.2982 & 0.4027 & 3.8431 & 3.2939 & 2.8744 \\
0.3904 & 0.1950 & 2.2103 & 1.9509 & 1.7397 \\
0.4455 & 0.1039 & 1.7404 & 1.6233 & 1.4578 \\
0.8128 & 0.0922 & 1.2732 & 1.1977 & 1.0697 \\
0.5852 & 0.2030 & 1.8910 & 1.7588 & 1.5767 \\
0.6004 & 0.2018 & 1.8776 & 1.7033 & 1.5589 \\
0.4965 & 0.2535 & 2.3603 & 2.0159 & 1.8080 \\
0.3999 & 0.2965 & 2.8013 & 2.4098 & 2.1535 \\
0.1956 & 0.4168 & 4.4209 & 3.7218 & 3.3392 \\
0.1002 & 0.4509 & 4.8115 & 4.1473 & 3.5836 \\
\hline
\end{tabular}

Table 3

EXPERIMENTAL VALUES FOR VISCOSITIES ( $\eta$ ) OF THE CYCLOHEXANE $\left(x_{1}\right)+$ CYCLOHEXANOL $\left(x_{2}\right)+$ CYCLOHEXANONE SYSTEM 


\begin{tabular}{|c|c|c|c|c|}
\hline & & \multicolumn{3}{|c|}{ Refractive index } \\
\cline { 3 - 5 }$x_{1}$ & $x_{2}$ & \multicolumn{3}{|c|}{ Temperature /K } \\
\hline 0.0981 & 0.1053 & 1.4515 & 1.4498 & 1.4485 \\
0.1462 & 0.1740 & 1.4500 & 1.4486 & 1.4473 \\
0.1957 & 0.2005 & 1.4494 & 1.4482 & 1.4470 \\
0.2161 & 0.2200 & 1.4490 & 1.4478 & 1.4464 \\
0.2986 & 0.3049 & 1.4486 & 1.4470 & 1.4460 \\
0.3993 & 0.3973 & 1.4480 & 1.4462 & 1.4452 \\
0.4484 & 0.4574 & 1.4458 & 1.4446 & 1.4436 \\
0.1079 & 0.7868 & 1.4595 & 1.4583 & 1.4568 \\
0.1501 & 0.6956 & 1.4578 & 1.4565 & 1.4552 \\
0.1994 & 0.5982 & 1.4551 & 1.4540 & 1.4525 \\
0.2514 & 0.4950 & 1.4533 & 1.4518 & 1.4502 \\
0.2982 & 0.4027 & 1.4496 & 1.4484 & 1.4470 \\
0.3904 & 0.1950 & 1.4460 & 1.4444 & 1.4426 \\
0.4455 & 0.1039 & 1.4406 & 1.4394 & 1.4382 \\
0.8128 & 0.0922 & 1.4347 & 1.4334 & 1.4320 \\
0.5852 & 0.2030 & 1.4400 & 1.4387 & 1.4372 \\
0.6004 & 0.2018 & 1.4394 & 1.4381 & 1.4368 \\
0.4965 & 0.2535 & 1.4427 & 1.4418 & 1.4402 \\
0.3999 & 0.2965 & 1.4456 & 1.4443 & 1.4430 \\
0.1956 & 0.4168 & 1.4532 & 1.4520 & 1.4502 \\
0.1002 & 0.4509 & 1.4548 & 1.4536 & 1.4522 \\
\hline
\end{tabular}

Table 4

EXPERIMENTAL VALUES FOR REFRACTIVE INDICES $\left(n_{0}\right)$ OF THE CYCLOHEXANE $\left(x_{1}\right)+$ CYCLOHEXANOL $\left(x_{2}\right)+$ CYCLOHEXANONE SYSTEM
Densities of the pure components and ternary mixtures were correlated with temperature using the relation [22]:

$$
\rho=a_{0}+a_{1} T
$$

Viscosities of the pure compounds and ternary solutions were correlated with temperature using the equation [22]:

$$
\eta=\eta_{0} e^{\frac{E_{a}}{R T}}
$$

where $\eta_{0}$ and $E_{a}$ are the adjustable parameters.

The adjustable parameters of these equations were estimated using the experimental data and a nonlinear regression analysis employing the Levenberg-Marquardt algorithm [23]. Tables 5 and 6 shows the fitting parameters along with the correlation square coefficient $\left(r^{2}\right)$ and standard deviation $(\sigma)$ calculated with equation:

$$
\sigma=\left[\frac{\sum\left(X_{e x p}-X_{c a l c}\right)^{2}}{m-n}\right]^{1 / 2}
$$

where $X$ is the value of the analysed property, $m$ is the number of data points and $n$ is the number of estimated parameters.

The values of the standard deviation $(\sigma)$ and the correlation square coefficient $\left(r^{2}\right)$ indicate that the equations tested are able to correlate good the experimental values of the densities and viscosities.

\section{Viscosity data modeling}

The viscosity correlation equations used for binary mixtures have been extended to ternary systems by introducing ternary adjustable parameters. The correlating ability of the Grunberg-Nissan equations with three binary parameters and respectively four parameters (three binary and one ternary) and also of the Heric-Brewer equation was tested in this work.

\begin{tabular}{|c|c|c|c|c|c|}
\hline$x_{1}$ & $x_{2}$ & $a_{0}$ & $10^{+} a_{1}$ & $10^{+} \sigma / \mathrm{g} \mathrm{cm}^{-3}$ & $r^{2}$ \\
\hline 1 & 0 & -1.0352 & -8.8 & 3.26 & 0.9945 \\
\hline 0 & 1 & 1.1785 & -7.8 & 1.63 & 0.9982 \\
\hline 0 & 0 & 1.1339 & -6.4 & 0.00 & 1.0000 \\
\hline 0.0981 & 0.1053 & 1.1021 & -5.9 & 2.04 & 0.9952 \\
0.1462 & 0.1740 & 1.1624 & -8.2 & 1.63 & 0.9984 \\
0.1957 & 0.2005 & 1.2038 & -9.9 & 6.12 & 0.9848 \\
0.2161 & 0.2200 & 1.1731 & -9.0 & 6.53 & 0.9791 \\
0.2986 & 0.3049 & 1.1453 & -8.6 & 4.90 & 0.9871 \\
0.3993 & 0.3973 & 1.1491 & -9.2 & 4.90 & 0.9887 \\
0.4484 & 0.4574 & 1.1162 & -8.4 & 0.82 & 0.9996 \\
0.1079 & 0.7868 & 1.1523 & -7.6 & 2.44 & 0.9958 \\
0.1501 & 0.6956 & 1.2012 & -9.5 & 5.30 & 0.9876 \\
0.1994 & 0.5982 & 1.1748 & -8.9 & 4.49 & 0.9899 \\
0.2514 & 0.4950 & 1.0987 & -6.8 & 0.82 & 0.9994 \\
0.2982 & 0.4027 & 1.1458 & -8.7 & 1.22 & 0.9992 \\
0.3904 & 0.1950 & 1.1123 & -8.0 & 3.26 & 0.9934 \\
0.4455 & 0.1039 & 1.1719 & -10.3 & 6.12 & 0.9860 \\
0.8128 & 0.0922 & 1.1283 & -10.9 & 8.57 & 0.9756 \\
0.5852 & 0.2030 & 1.1868 & -11.6 & 1.63 & 0.9992 \\
0.6004 & 0.2018 & 1.1375 & -10.0 & 4.90 & 0.9904 \\
0.4965 & 0.2535 & 1.1248 & -9.0 & 5.71 & 0.9840 \\
0.3999 & 0.2965 & 1.0902 & -7.4 & 0.00 & 1.0000 \\
0.1956 & 0.4168 & 1.1280 & -7.4 & 0.82 & 0.9995 \\
0.1002 & 0.4509 & 1.20291 & -9.3 & 2.86 & 0.9962 \\
\hline
\end{tabular}

Table 5

PARAMETERS FOR DENSITY DATA, STANDARD DEVIATION AND CORRELATION SQUARE COEFFICIENT FOR CYCLOHEXANE $\left(x_{1}\right)$ - CYCLOHEXANOL $\left(x_{2}\right)$ - CYCLOHEXANONE 


\begin{tabular}{|c|c|c|c|c|c|}
\hline$x_{1}$ & $x_{2}$ & $10^{2} \cdot \eta_{0}$ & $E_{\mathrm{a}} / \mathrm{kJ}^{\mathrm{mol}} \mathrm{l}^{-1}$ & $\sigma / \mathrm{mPa} \mathrm{s}$ & $r^{2}$ \\
\hline 1 & 0 & 54.9 & 12.6 & 0.005 & 0.9953 \\
\hline 0 & 1 & $2.05^{-}$ & $30.7^{-}$ & 1.517 & 0.9795 \\
\hline 0 & 0 & 69.9 & 14.1 & 0.005 & $0.9993^{-}$ \\
\hline 0.0981 & 0.1053 & 46.8 & 15.2 & 0.004 & 0.9996 \\
\hline 0.1462 & 0.1740 & 10.3 & 19.1 & 0.027 & 0.9918 \\
\hline 0.1957 & 0.2005 & 11.7 & 18.8 & 0.021 & 0.9945 \\
\hline 0.2161 & 0.2200 & 22.6 & 17.2 & 0.020 & 0.9949 \\
\hline 0.2986 & 0.3049 & 47.7 & 15.6 & 0.024 & 0.9926 \\
\hline 0.3993 & 0.3973 & 4.16 & 22.1 & 0.005 & 0.9999 \\
\hline 0.4484 & 0.4574 & 2.46 & 23.7 & 0.024 & 0.9981 \\
\hline 0.1079 & 0.7868 & 0.085 & 35.4 & 0.129 & 0.9985 \\
\hline 0.1501 & 0.6956 & 0.43 & 30.5 & 0.013 & 0.9999 \\
\hline 0.1994 & 0.5982 & 1.86 & 26.0 & 0.092 & 0.9939 \\
\hline 0.2514 & 0.4950 & 4.32 & 22.9 & 0.061 & 0.9921 \\
\hline 0.2982 & 0.4027 & 5.52 & 21.5 & 0.017 & 0.9987 \\
\hline 0.3904 & 0.1950 & 15.3 & 17.7 & 0.005 & 0.9996 \\
\hline 0.4455 & 0.1039 & 88.1 & 12.9 & 0.027 & 0.9646 \\
\hline 0.8128 & 0.0922 & 72.6 & 12.6 & 0.026 & 0.9343 \\
\hline 0.5852 & 0.2030 & 83.3 & 13.2 & 0.028 & 0.9679 \\
\hline 0.6004 & 0.2018 & 65.7 & 13.8 & 0.004 & 0.9994 \\
\hline 0.4965 & 0.2535 & 6.39 & 20.0 & 0.037 & 0.9827 \\
\hline 0.3999 & 0.2965 & 8.74 & 19.7 & 0.033 & 0.9896 \\
\hline 0.1956 & 0.4168 & 7.43 & 21.1 & 0.090 & 0.9729 \\
\hline 0.1002 & 0.4509 & 6.41 & 21.7 & 0.004 & 0.9999 \\
\hline
\end{tabular}

The Grunberg-Nissan equation [24] with three binary parameters is:

$$
\ln \eta=x_{1} \ln \eta_{1}+x_{2} \ln \eta_{2}+x_{3} \ln \eta_{3}+x_{1} x_{2} d_{12}+x_{1} x_{3} d_{13}+x_{2} x_{3} d_{23}
$$

The Grunberg-Nissan equation [24] with four parameters is:

$$
\ln \eta=x_{1} l n \eta_{1}+r_{2} ! n \eta_{2}+x_{2} l n \eta_{3}+x_{1} x_{2} d_{12}+x_{1} x_{3} d_{13}+x_{2} x_{3} d_{23}+r_{1} x_{2} x_{3} d_{123}
$$

The Heric-Brewer equation [25] for ternary system is:

$$
\begin{gathered}
\ln \eta=x_{1} \ln \eta_{1}+x_{2} \ln \eta_{2}+x_{3} \ln \eta_{3}+x_{1} \ln M_{1}+x_{2} \ln M_{2}+x_{3} \ln M_{3} \\
-\ln \left(x_{1} M_{1}+x_{2} M_{2}+x_{3} M_{3}\right)+x_{1} x_{2}\left[\alpha_{12}+\alpha_{21}\left(x_{1}-x_{2}\right)\right] \\
+x_{1} x_{3}\left[\alpha_{13}+\alpha_{31}\left(x_{1}-x_{3}\right)\right]+x_{2} x_{3}\left[\alpha_{23}+\alpha_{32}\left(x_{2}-x_{3}\right)\right]+x_{1} x_{2} x_{3} \alpha_{123}
\end{gathered}
$$

In the equations $6-8 \eta$, and $\eta_{1}, \eta_{2}, \eta_{3}$ are the dynamic viscosities of the liquid mixtures and of the pure components 1,2 and $3, X_{1}, x_{2}, x_{3}$ are the mole fractions, $M_{1}$, $M_{2}$ and $M_{3}$ are the molecular masses, $T$ is the temperature; $d_{12^{\prime}}^{2} d_{13^{\prime}} d_{23^{\prime}}, \alpha_{12^{\prime}}, \alpha_{21^{\prime}}, \alpha_{13^{\prime}}, \alpha_{31}, \alpha_{23,} \alpha_{32}$ are the binary parameters and ${ }_{123^{\prime}}{ }_{123}$ are the ternary parameters. These coefficients were estimated using the experimental viscosity data and a non-linear regression analysis employing the Levenberg-Marquardt algorithm [23].
Table 7 shows the parameters calculated and the standard deviations $(\sigma)$ calculated using the equation 5 , where $X_{\text {exp }}$ is the experimental viscosity, $X_{\text {cal }}$ is the calculated viscosity and $n$ is the number of adjustable parameters. Figure 1 shows experimental and calculated values (equations 6-8) of viscosities at $298.15 \mathrm{~K}$.

As can be seen in figure 1 the values calculated with the Heric-Brewer equation are closer to the bisector of the diagram which shows that this equation can be used with good results for the correlation of viscosity.

\begin{tabular}{|c|c|c|c|c|}
\hline Equation & Parameters and & \multicolumn{3}{|c|}{ Temperature / } \\
\cline { 3 - 5 } & $\sigma(m$ Pas $)$ & 293.15 & 298.15 & 303.15 \\
\hline Grunberg-Nissan with & $d_{12}$ & 2.1380 & -2.3512 & -2.3006 \\
three parameters & $d_{13}$ & 0.1997 & 0.4558 & 0.4902 \\
G-N(1) & $d_{23}$ & -2.6336 & -2.9466 & -2.8045 \\
& $\sigma$ & 0.029 & 0.036 & 0.042 \\
\hline Grunberg-Nissan with & $d_{12}$ & -2.3721 & -2.5725 & -2.6890 \\
four parameters & $d_{13}$ & -0.0397 & 0.2294 & 0.0929 \\
G-N (2) & $d_{23}$ & -2.8463 & -3.1476 & -3.1574 \\
& $d_{123}$ & 2.5617 & 2.4213 & 4.2509 \\
& $\sigma$ & 0.027 & 0.035 & 0.037 \\
\hline & $\alpha_{12}$ & -2.1488 & -2.2535 & -2.3766 \\
& $\alpha_{21}$ & -2.8717 & 1.5984 & 2.3572 \\
& $\alpha_{13}$ & -0.3400 & -0.2671 & -0.4457 \\
Heric-Brewer & $\alpha_{31}$ & 2.8354 & -0.9158 & -1.4429 \\
(H-B) & $\alpha_{23}$ & -2.9333 & -2.9248 & -2.8443 \\
& $\alpha_{32}$ & -3.5486 & 0.0957 & 0.6828 \\
& $\alpha_{123}$ & 3.2183 & 2.3528 & 4.0364 \\
& $\sigma$ & 0.020 & 0.024 & 0.024 \\
\hline
\end{tabular}

Table 7

PARAMETERS FOR EQUATIONS OF GRUNBERG-NISSAN AND HERIC-BREWER AND STANDARD DEVIATIONS AT DIFFERENT TEMPERATURE 


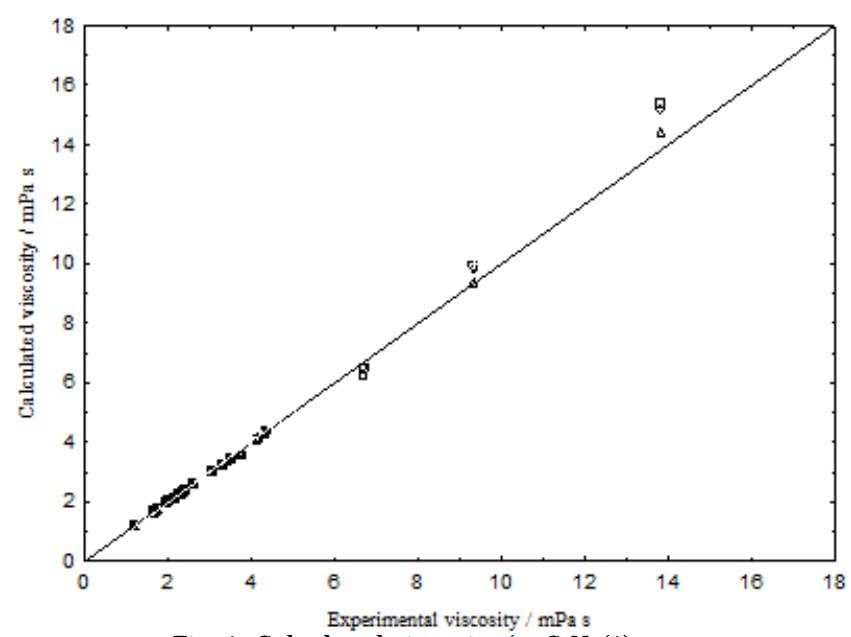

Fig. 1. Calculated viscosity ( G-N (1),

$\diamond \mathrm{G}-\mathrm{N}(2), \triangle \mathrm{H}-\mathrm{B}$ ) versus experimental viscosity (continuous line) at $298.15 \mathrm{~K}$

Modeling refractive index data

The refractive indices were compared with the predicted results from the mixing rules proposed by AragoBiot, Dale-Glastone, Newton and Lorentz-Lorenz [26-30]:

Arago - Biot (A-B):

$$
n_{D}=n_{D 1} \phi_{1}+n_{D 2} \phi_{2}+n_{D 3} \phi_{3}
$$

Dale - Glastone (D-G):

$n_{D}-1=\left(n_{D 1}-1\right) \phi_{1}+\left(n_{D 2}-1\right) \phi_{2}+\left(n_{D 3}-1\right) \phi_{3}$

Newton (Nw) :

$n_{D}^{2}-1=\left(n_{D 1}^{2}-1\right) \phi_{1}+\left(n_{D 2}^{2}-1\right) \phi_{2}+\left(n_{D 3}^{2}-1\right) \phi_{3}$

Lorentz - Lorenz (L-L):

$$
\frac{n_{\bar{D}}^{2}-1}{n_{\tilde{D}}^{2}+2}=\left(\frac{n_{D_{1}}^{2}-1}{n_{D_{1}}+2}\right) \phi_{1}+\left(\frac{n_{D_{2}}^{2}-1}{n_{\hat{D}_{2}}+2}\right) \phi_{2}+\left(\frac{n_{D_{3}}^{2}-1}{n_{D_{3}}+2}\right) \phi_{3}
$$

where $n_{D^{\prime}}, n_{D_{1}}, n_{D 2}, n_{\mathrm{D} 2}$ are the refractive indices of the solution, of component 1, 2 and 3 respectively, and $\phi_{1}, \phi_{2}$ and $\phi_{3}$ are the volume fractions for component 1,2 and 3 respectively.

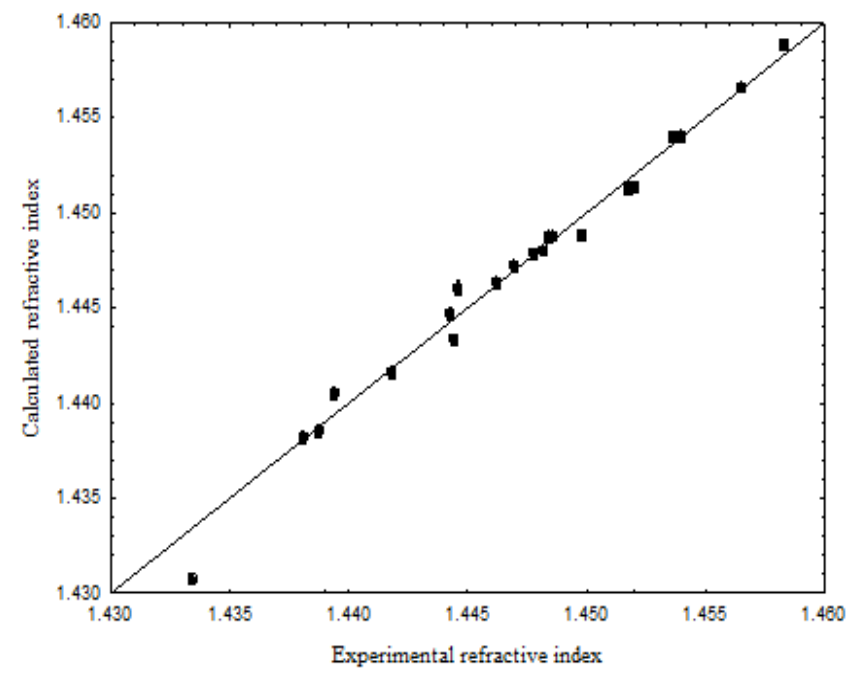

Fig. 2. Calculated refractive index ( A-B, $\diamond \mathrm{D}-\mathrm{G}, \Delta \mathrm{Nw}, \bullet \mathrm{L}-\mathrm{L})$ versus experimental refractive index (continuous line) at $298.15 \mathrm{~K}$.

Table 8

VALUES OF STANDARD DEVIATION OF MIXING RULES $A-B, D-G, N W, L-L$

\begin{tabular}{|c|c|c|c|c|}
\hline \multirow{2}{*}{$\begin{array}{c}\text { Temperature } \\
\text { K }\end{array}$} & \multicolumn{4}{|c|}{$\sigma \cdot 10^{+}$} \\
\cline { 2 - 4 } & \multicolumn{3}{|c|}{ Equation } \\
\hline 293.15 & 9.25 & 9.25 & 9.44 & 9.12 \\
\hline 298.15 & 8.72 & 8.72 & 8.80 & 8.72 \\
\hline 303.15 & 7.74 & 7.74 & 7.87 & 7.70 \\
\hline
\end{tabular}

Table 5 shows the standard deviation values calculated with the equation 5 , where $X$ is the experimental refractive index and $X_{\text {calc }}$ is the calculated refractive index. Figure 2 shows experimental and calculated values (equations 9-12) of refractive indices at $298.15 \mathrm{~K}$.

From the data presented in table 8 , it can be noticed that the Lorentz-Lorenz equation shows the lowest values of the standard deviation for 293.15 and $303.15 \mathrm{~K}$. For 298.15 K the Arago-Biot, Dale-Glastone and Lorentz-Lorenz equations have the same standard deviation value. These results show the Lorentz-Lorenz is the best equation to

\begin{tabular}{|c|c|c|c|c|c|c|}
\hline \multirow[t]{2}{*}{$x_{1}$} & \multirow[t]{2}{*}{$x_{2}$} & \multicolumn{3}{|c|}{$\Delta G^{-} / \mathrm{kJ} \mathrm{mol}^{-1}$} & \multirow{2}{*}{$\begin{array}{c}\Delta H^{* /} \\
\mathrm{kJ} \mathrm{mol}^{-1}\end{array}$} & \multirow{2}{*}{$\begin{array}{c}\Delta S^{\# /} \\
\mathrm{J} \mathrm{mol}^{-1} \mathrm{~K}^{-1}\end{array}$} \\
\hline & & 293.15 & 298.15 & 303.15 & & \\
\hline 1 & 0 & 14.20 & 14.25 & 14.31 & 10.98 & -10.98 \\
\hline 0 & 1 & 23.78 & 23.67 & 23.56 & 30.23 & 21.99 \\
\hline 0 & 0 & 14.88 & 14.93 & 14.97 & 12.26 & -8.97 \\
\hline 0.0981 & 0.1053 & 15.88 & 15.90 & 15.93 & 14.59 & -5.42 \\
\hline 0.1462 & 0.1740 & 16.13 & 16.11 & 16.08 & 17.63 & 5.09 \\
\hline 0.1957 & 0.2005 & 16.11 & 16.10 & 16.09 & 17.02 & 3.07 \\
\hline 0.2161 & 0.2200 & 16.18 & 16.19 & 16.20 & 15.63 & -1.87 \\
\hline 0.2986 & 0.3049 & 16.46 & 16.50 & 16.55 & 14.07 & -8.17 \\
\hline 0.3993 & 0.3973 & 19.46 & 19.44 & 19.42 & 20.47 & 3.46 \\
\hline 0.4484 & 0.4574 & 17.41 & 17.32 & 17.24 & 22.42 & 17.08 \\
\hline 0.1079 & 0.7868 & 20.78 & 20.56 & 20.33 & 33.97 & 45.00 \\
\hline 0.1501 & 0.6956 & 19.75 & 19.59 & 19.44 & 28.90 & 31.20 \\
\hline 0.1994 & 0.5982 & 18.86 & 18.75 & 18.65 & 24.83 & 20.38 \\
\hline 0.2514 & 0.4950 & 17.86 & 17.80 & 17.73 & 21.51 & 12.44 \\
\hline 0.2982 & 0.4027 & 17.17 & 17.12 & 17.07 & 20.01 & 9.70 \\
\hline 0.3904 & 0.1950 & 15.85 & 15.84 & 15.84 & 16.34 & 1.65 \\
\hline 0.4455 & 0.1039 & 15.31 & 15.38 & 15.44 & 11.30 & -13.67 \\
\hline 0.8128 & 0.0922 & 14.77 & 14.83 & 14.90 & 10.84 & -13.38 \\
\hline 0.5852 & 0.2030 & 15.59 & 15.67 & 15.74 & 11.35 & -14.46 \\
\hline 0.6004 & 0.2018 & 15.57 & 15.63 & 15.69 & 11.99 & -12.19 \\
\hline 0.4965 & 0.2535 & 16.06 & 16.02 & 15.98 & 18.16 & 7.18 \\
\hline 0.3999 & 0.2965 & 16.45 & 16.42 & 16.39 & 18.18 & 5.92 \\
\hline 0.1956 & 0.4168 & 17.42 & 17.38 & 17.35 & 19.55 & 7.27 \\
\hline 0.1002 & 0.4509 & 17.59 & 17.54 & 17.49 & 20.27 & 9.16 \\
\hline
\end{tabular}
estimate the refractive index of this ternary system.
Table 9

VALUES OF $\Delta \mathrm{G}^{\#}, \Delta \mathrm{H}^{\#}, \Delta \mathrm{S}^{\#}$ FOR CYCLOHEXANE $\left(\mathrm{X}_{1}\right)+$ CYCLOHEXANOL $\left(\mathrm{X}_{2}\right)+$ CYCLOHEXANONE SYSTEM 
Thermodynamic functions of activation

The energies of activation of viscous flow were calculated with equation:

$$
\begin{gathered}
\eta=\frac{h N}{V} \exp \left(\frac{\Delta G^{\#}}{R T}\right) \\
\Delta G^{\#}=\Delta H^{\#}-T \Delta S^{\#}
\end{gathered}
$$

where:

and $\eta$ is viscosity of a liquid mixtures, $h$ is Planck's constant, $N$ is Avogadro's number, $V$ is the molar volume of the solution, $R$ is general gas constant, $T$ is temperature, $\Delta G^{\#}, \Delta H^{\#}$ and $\Delta S^{*}$ are the molar Gibbs energy, enthalpy and entropy of activation of viscous flow.

The plots of $\ln (\eta V / h N)$ vs $1 / T$ are linear in the temperature range 293.15 to $303.15 \mathrm{~K}$ and the values of $\Delta H^{\#}$ and $\Delta S^{\#}$ were obtained by the corresponding slopes and the intercepts. The values of $\Delta G^{\#}$ were calculated with equation 14. The values of thermodynamic functions of activation of viscous flow as a function of composition are presented in table 9.

The values of $\Delta \mathrm{G}^{\#}$ and $\Delta \mathrm{H}^{\#}$ are positive for the ternary system of cyclohexane + cyclohexanol + cyclohexanone suggesting specific interactions, like $\mathrm{H}$-bonding, between solution components. These values increase with the cyclohexanol concentration of solution at temperature constant. The values of the activation entropy of viscous flow are positive for cyclohexanol and negative for cyclohexane and cyclohexanone showing that overall molecular order due to activated complex formation increase for non-associating component and decrease in case of alcohol due the breaking of $\mathrm{H}$-bonds. The positive $\Delta S^{\#}$ values are obtained for solutions concentrated in cyclohexanol and become negative with decreasing its concentration in solution. These positive values of $\Delta S^{\#}$ for cyclohexanol and for the solutions concentrated in alcohol show a less overall molecular order due to activated complex formation for viscous flow.

\section{Conclusions}

The densities, viscosities and refractive indices of ternary mixtures of cyclohexane + cyclohexanol + cyclohexanone were measured experimentally at three temperatures $(293.15,298.15$ and $303.15 \mathrm{~K})$ over the entire composition range. The density and viscosity of the solutions studied in this paper can be correctly estimated at different temperatures using a linear equations and Guzman equation respectively.

Grunberg-Nissan with three parameters and four parameters and Heric-Brewer models have been used to calculate viscosity coefficients and these were compared with experimental data for the ternary mixtures. The results of these correlations indicate that Heric-Brewer model is the best to describe viscosities of the ternary mixtures. Four mixing rules were tested to estimate the refractive index and these results were compared with the experimental values. The best results were obtained using the Lorentz-Lorenz equation. The energies of activation of viscous flow were calculated. The values of $\Delta H^{\#}$ and $\Delta G^{\#}$ are positive at all of the temperatures and in the whole concentration range. The values of $\Delta S^{\#}$ are positive for cyclohexanol and solutions concentrated in cyclohexanol and negative for cyclohexane, cyclohexanone and solutions diluted in alcohol.

\section{References}

1.SHARMA, V.K., DUA, R., SHARMA, D., J. Chem. Thermodynamics, 78, no. 11, 2014, p. 241

2.CRISCIU, A., SECUIANU, C., FEROIU, V., Rev. Chim. (Bucharest), 65, no. 1,2014, p. 76

3.BUDEANU, M.M., RADU, S., DUMITRESCU, V., Rev. Chim. (Bucharest), 61, no. 3, 2010, p. 322

4.ZHANG, Z., JIA, P., HUANG, D., DU, M.Lv.Y., LI, W., J. Chem. Eng. Data, 58, no. 11, 2013, p. 3054

5.PATNAIK, P., A Comprehensive Guide to the Hazardous Properties of Chemical Substances, third ed., John Wiley $\&$ Sons, New Jersey, USA, 2007

6.ALI, A., ABIDA, HYDER, S., Phys. Chem. Liq., 42, no. 4, 2004, p. 411 7.CIOCIRLAN, O., TEODORESCU, M., DRAGOESCU, D., IULIAN, O., BARHALA, A., J. Chem. Eng. Data., 55, no. 9, 2010, p. 3891

8.RAFIEE, H.R., RANJ BAR, S., POURSALMAN, F., J. Chem. Thermodyn., 54, no. 11, 2012, p. 266

9.KUMARI, P.G., VENKATESU, P., HOFMAN, T., RAO, M.V.P., J. Chem. Eng. Data, 55, no. 1, 2010, p. 69

10.LI, G., LI, N., WANG, X., SHENG, X., LI, S., WANG, A., CONG, Y., WANG, X., ZHANG, T., Energy Fuel, 28, no. 8, 2014, p. 5112

11.JIANG, H., QU, Z., LI, Y., HUANG, J., CHEN, R., XING, W., Chem. Eng. J., 284, 2016, p. 724

12.ZHANG, N., ZHANG, J., ZHANG, Y., BAI, J., HUO, T. and WEI, X., Fluid Phase Equilibria, 313, 2012, p. 7

13.WEISSBERGER, A., Physical methods of Organic Chemistry Interscience Publishers Inc, (New York), 1959

14.NAIN, A.K, ANSARI, S., and ALI, A., J. Solution Chem., 43, no. 6, 2014, p. 1032

15.YANG, C., LIU, Z., LAl, H., MA, P., J. Chem. Thermodynamics, 39, no. 1, 2007, p.28

16.RIDDICH, J.A., BUNGER, W.B., SAKANO, T.K., Organic Solvent, Wiley-Interscience, New York, 1986

17.BENSON, G.C., MURAKAMI, S., JONES, D.E.G., J. Chem. Thermodynamics, 3, no. 5, 1971, p.719

18.ALI, A., NAIN, A.K., CHAND, D., LAL, B., Phys. Chem. Liq., 45, no. 1,2007, p.79

19.REDDY RAYAPA, K., KUMAR KARUNA BALA, D., RAO SRINIVASA, G., ANILA, P., RAMBABU, C., Thermochimica Acta, 590, 2014, p.116 20.PALAIOLOGOU, M.M., ARIANAS, G.K., TSIERKEYOS, N.G., J. Solution Chem., 35, no. 11, 2006, p.1551

21.LANGE, N.A., Handbook of Chemistry, Mc Graw Hill, New York, 1973

22.J ACQUEMIN, J., HUSSON, P., PADUA, A.A.H \& MAJER, V., Green Chem., 8, no. 2, 2006, p. 162

23.MARQUARDT, D.W., J. Soc. Indust. Appl. Math., 11, no. 2, 1963, p. 431

24.GRUNBERG, L., NISSAN, A.H., Nature, 164, no. 41751949, p.799

25.HERIC, E. L., BREWER, J. G., J. Chem. Eng. Data, 12, 1967, p.574

26.ARAGO, D.F.J., BIOT, J .B., Mem. Acad. Fr., 15, 1806, p.7

27.DALE, D. and GLADSTONE, F., Philos. Trans. R. Soc., 148, 1858, p.887

28.KURTZ, S.S. and WARD, A.L.J., Franklin Inst., 222, 1936, p.563

29.LORENTZ, H.A., Weid. Ann., 9, 1880, p.641

30.LORENZ, L., Weid. Ann., 11, 1880, p.70.

Manuscript received: 24.05 .2018 